\title{
Laser flare intensity in diabetics: correlation with retinopathy and aqueous protein concentration
}

\author{
Masanori Ino-ue, Atsushi Azumi, Hisamitsu Shirabe, Yasutomo Tsukahara, Misao Yamamoto
}

\begin{abstract}
The laser flare intensity in diabetics, measured with the scattering of a light beam, was evaluated and compared with actual aqueous protein concentration obtained during surgery. Measurement of the laser flare intensity in 120 diabetics and 108 normal subjects was performed with the laser flare cell meter. (FC1000 Kowa, Tokyo). Aqueous protein concentration in 26 diabetics and six controls who underwent intraocular surgery was measured by the method of Bradford. No significant difference in the laser flare intensity was found between normal subjects and diabetics without retinopathy. A significant increase in the laser flare intensity was observed after six decades in diabetics with background retinopathy and all with proliferative retinopathy. The laser flare intensity correlated with the duration of diabetes mellitus. There was a significant linear relation between the laser flare intensity and actual aqueous protein concentration. The linear regression formula was $X=Y^{1.39} \times 1.02$ ( $\mathbf{X}=$ protein concentration, $\mathrm{mg} / \mathrm{dl} ; \mathbf{Y}=$ flare intensity, photon counts/ms). The precise value of the laser flare intensity provides a new indicator to evaluate the diabetic change in the function of the ocular barrier.

(Br F Ophthalmol 1994; 78: 694-697)
\end{abstract}

In diabetics, histopathological studies, ${ }^{12}$ iris fluorescein angiography, ${ }^{3}$ and fluorophotometry ${ }^{4}$ revealed the dysfunction of the blood-aqueous barrier as well as the blood-retinal barrier. The breakdown of the blood-aqueous barrier resulted in an increase of protein as flare and cells as floaters in the aqueous humour. Until now, it has been difficult to detect the exact amount of protein in a non-invasive manner.

The laser flare cell meter was developed to quantify the flare intensity and number of cells in the aqueous humour in vivo. ${ }^{5}$ The laser flare cell meter provides a precise, objective, and noninvasive measurement of aqueous flare. Clinical applications of this instrument have been per- formed in uveitis, ${ }^{6}$ postsurgical inflammation, ${ }^{78}$ pseudoexfoliation syndrome, ${ }^{9}$ retinal vein occlusion, ${ }^{111}$ and normal subjects. ${ }^{12}{ }^{13}$ Our previous study ${ }^{14}$ is and that of Oshika $e a^{16}{ }^{16}$ indicated that the laser flare cell meter is a useful instrument in evaluating the diabetic change of the eye. In this report we employed this instrument to measure the laser flare intensity in diabetics and normal subjects at various ages. Furthermore, actual aqueous protein concentration was measured in the eyes of diabetics who underwent intraocular surgery. The correlation between the aqueous flare intensity and actual aqueous protein concentration was affirmed.

\section{Subjects and methods}

One hundred and twenty diabetics between the ages of 12 and 68 (mean $48 \cdot 1$ ) years were chosen as subjects. We excluded eyes with moderate cataract and glaucoma. The ocular fundus condition of subjects included 67 eyes with no retinopathy, 83 eyes with background retinopathy, and 44 eyes with proliferative retinopathy. In seven eyes rubeosis iridis was observed under slit-lamp examination; no patients had received photocoagulation. Of 108 normal subjects, aged 10-69 (mean 42.1) years, 147 eyes had no ocular diseases, except for moderate refractive errors.

Measurement of the laser flare intensity was performed with the laser flare cell meter (FC1000 Kowa, Tokyo). The principle of the laser flare cell meter has been described by Sawa et al. ${ }^{5}$ The sensitivity and reliability of the method has been confirmed. ${ }^{781718}$ The means and the standard deviations were calculated from five separate measurements. The values were selected; each background count was less than 20 and the difference between backgrounds 1 and 2 was under $15 \%$. Simultaneously ophthalmoscopic examination was carried out.

Aqueous humour of 26 diabetics and six nondiabetic subjects who underwent cataract or glaucoma surgery was collected by limbal paracentesis and immediately frozen at $-80^{\circ} \mathrm{C}$ until analysed. The procedure had been explained to patients and their informed consent obtained.

Table 1 Laser flare intensity (photon count/ms) of normal subjects and diabetics at various decades (SD)

\begin{tabular}{llllll}
\hline & & & & Proliferative type \\
\cline { 3 - 6 } Age & Normal & No retinopathy & Background type & Rubeosis $(-)$ & Rubeosis $(+)$ \\
\hline $10-19$ & $3 \cdot 8(1 \cdot 0)(\mathrm{n}=20)$ & $3 \cdot 4(1 \cdot 0)(\mathrm{n}=14)$ & $2 \cdot 8(0 \cdot 6)(\mathrm{n}=2)$ & & \\
$20-29$ & $4 \cdot 5(1 \cdot 0)(\mathrm{n}=27)$ & $3 \cdot 6(0 \cdot 9)(\mathrm{n}=12)$ & $4 \cdot 5(1 \cdot 6)(\mathrm{n}=10)$ & $11 \cdot 2(5 \cdot 3)(\mathrm{n}=5)^{\star}$ & \\
$30-39$ & $4 \cdot 9(1 \cdot 3)(\mathrm{n}=22)$ & $4 \cdot 0(0 \cdot 8)(\mathrm{n}=7)$ & $5 \cdot 5(1 \cdot 4)(\mathrm{n}=10)$ & $15 \cdot 4(7 \cdot 4)(\mathrm{n}=4)^{\star}$ & \\
$40-49$ & $5 \cdot 0(1 \cdot 7)(\mathrm{n}=21)$ & $4 \cdot 2(0 \cdot 9)(\mathrm{n}=6)$ & $4 \cdot 5(0 \cdot 8)(\mathrm{n}=7)$ & $12 \cdot 5(3 \cdot 0)(\mathrm{n}=11)^{\star}$ & $22 \cdot 1(\mathrm{n}=1)$ \\
$50-59$ & $5 \cdot 7(1 \cdot 2)(\mathrm{n}=30)$ & $5 \cdot 6(1 \cdot 7)(\mathrm{n}=19)$ & $7 \cdot 4(3 \cdot 1)(\mathrm{n}=25)$ & $14 \cdot 3(4 \cdot 1)(\mathrm{n}=10)^{\star}$ & $35 \cdot 3(10 \cdot 2)(\mathrm{n}=3)^{\star}$ \\
$60-69$ & $5 \cdot 7(1 \cdot 7)(\mathrm{n}=27)$ & $5 \cdot 0(1 \cdot 3)(\mathrm{n}=9)$ & $7 \cdot 3(2 \cdot 8)(\mathrm{n}=29)^{\star \star \star}$ & $15 \cdot 8(7 \cdot 2)(\mathrm{n}=14)^{\star}$ & $40 \cdot 1(19 \cdot 3)(\mathrm{n}=3)^{\star \star}$ \\
Total & $5 \cdot 0(1 \cdot 5)(\mathrm{n}=147)$ & $4 \cdot 4(1 \cdot 5)(\mathrm{n}=67)$ & $6 \cdot 4(2 \cdot 8)(\mathrm{n}=83)$ & $13 \cdot 9(6 \cdot 5)(\mathrm{n}=44)^{\star}$ & $37 \cdot 3(15 \cdot 7)(\mathrm{n}=7)^{\star}$ \\
\hline
\end{tabular}

${ }^{\star} \mathrm{p}<0.001 ;{ }^{\star \star} \mathrm{p}<0 \cdot 01 ;{ }^{\star \star \star} \mathrm{p}<0.05$. 
Table 2 Laser flare intensity and duration of diabetes mellitus

\begin{tabular}{llll}
\hline & & \multicolumn{2}{l}{$\begin{array}{l}\text { Laser flare intensity (photon } \\
\text { count/ms) }\end{array}$} \\
\cline { 3 - 4 } $\begin{array}{l}\text { Duration } \\
\text { (years) }\end{array}$ & $\begin{array}{l}\text { Average age } \\
\text { (years) }\end{array}$ & Diabetics & (Control) \\
\hline-5 & $47 \cdot 04$ & $4 \cdot 28$ & $(5 \cdot 22)$ \\
$6-10$ & $52 \cdot 76$ & $7 \cdot 51$ & $(5 \cdot 44)$ \\
$11-15$ & $53 \cdot 28$ & $9 \cdot 68$ & $(5 \cdot 46)$ \\
$16-20$ & $59 \cdot 13$ & $11 \cdot 3$ & $(5 \cdot 7)$ \\
$21-$ & $54 \cdot 78$ & $13 \cdot 28$ & $(5 \cdot 52)$ \\
\hline
\end{tabular}

Numbers in parenthesis present laser flare intensity of norma control after ages matched to each diabetic group.

Retinopathy was not observed in eight eyes of diabetics (age range 39-88 (mean 57.9) years), background retinopathy was present in six eyes (age range 46-76 (mean 66.6) years), and proliferative and then burnout retinopathy by panretinal photocoagulation in 10 eyes (age range 54-62 (mean 58.0) years). In two eyes of patients (aged 54 and 62, mean 58.0 years) rubeosis was observed under slit-lamp examination. The age of non-diabetic subjects with cataract or glaucoma ranged between 60 and 72 (mean $65 \cdot 1$ ) years. The laser flare intensity was measured before surgery. Total protein was measured by a Bio-Rad protein assay (Bradford's method) with bovine serum albumin as a standard. ${ }^{19}$

The laser flare intensity was not converted to the protein concentration. The value was statistically analysed with the non-parametric Wilcoxon rank sum and Spearman rank test and Pearson's correlation coefficient.

\section{Results}

The average values of the laser flare intensities of diabetics and controlled subjects at various decades are shown in Table 1 . The laser flare intensities in normal subjects were significantly higher in the group aged 50 years and over (Wilcoxon rank sum test, $\mathrm{p}<0.001$ ). The laser flare intensity of diabetics was compared with those with retinopathy. There was no difference between diabetics without retinopathy and normal subjects. In the background retinopathy group, the laser flare intensity in the sixth decade was higher than in normal subjects (Wilcoxon rank sum test, $p<0.05)$. There was no significant

Figure 1 Relation between laser flare intensity and aqueous protein concentration.

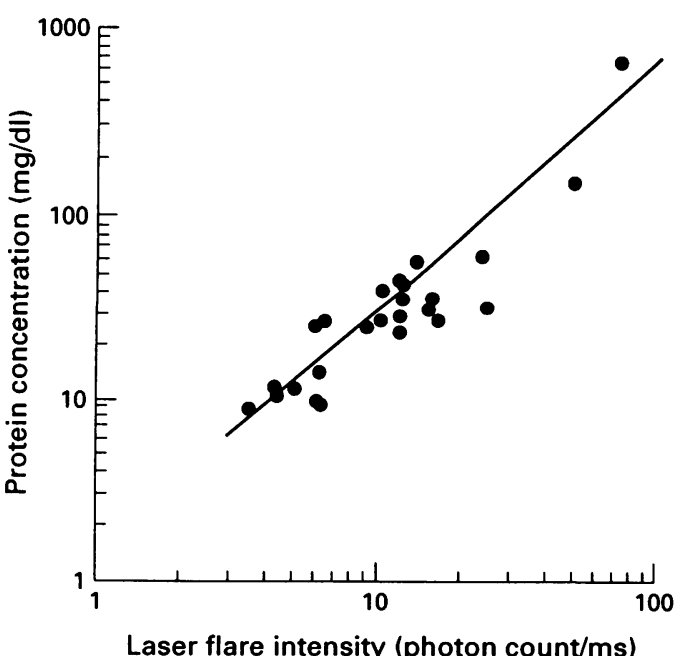

Laser flare intensity (photon count/ms)
Table 3 Aqueous protein concentration $(S D)$ in diabetics

\begin{tabular}{lc}
\hline Cases & Protein concentration $(m g / d l)$ \\
\hline Non-diabetics & $13 \cdot 1(6 \cdot 9)(\mathrm{n}=6)^{\star}$ \\
Diabetics & $12 \cdot 9(6 \cdot 5)(\mathrm{n}=8)$ \\
$\quad$ No retinopathy & $27 \cdot 2(10 \cdot 5)(\mathrm{n}=6)^{\star}$ \\
Background retinopathy & $37 \cdot 6(12 \cdot 7)(\mathrm{n}=10)^{\star}$ \\
$\quad$ Proliferative retinopathy & Burnt-out, rubeosis $(-)$ \\
$\quad$ Rubeosis $(+)$ & $385 \cdot 7(149 \cdot 2)(\mathrm{n}=2)$ \\
\hline${ }^{\star} \mathrm{p}<0 \cdot 05$. &
\end{tabular}

${ }^{\star} \mathrm{p}<0 \cdot 05$

difference below the fifth decade. Significant differences were observed between the proliferative group and normal subjects in all decades (Wilcoxon rank sum test, $\mathrm{p}<0.001$ ). The flare intensity in rubeosis iridis was remarkably higher than in other conditions. The flare intensity increased with progression of retinopathy.

The relation between the laser flare intensity and duration of diabetes mellitus was analysed. The diabetics were divided into five groups according to the duration of diabetes mellitus as shown in Table 2 . In the under 5 year age group, no retinopathy was observed in $75 \%$, however, background retinopathy was seen in $25 \%$. In the 6-15 year age group and over 16 year age group, no retinopathy was observed in $13 \%$ and $0 \%$, background retinopathy was present in $56 \%$ and $33 \%$, and proliferative retinopathy in $31 \%$ and $67 \%$ respectively. Patients with a long duration of diabetes had more retinopathy and the average age was high as shown in Table 2. Thus, the average values of the laser flare intensity of each diabetic group were compared with those of normal individuals of the same age group. Over a 6 year duration the laser flare intensity was significantly higher than in normal subjects (Wilcoxon rank sum test, $\mathrm{p}<0.01$ ). The flare intensity in diabetics increased significantly with the duration of diabetes mellitus depending on the degree of retinopathy (Spearman rank correlation coefficient $r=0.54, \mathrm{p}<0.001$ ).

Correlation between the laser flare intensity and actual aqueous protein concentration in diabetics was examined. There was a statistically significant correlation between the flare intensity and the aqueous protein concentration when plotted on a logarithmic scale, as shown in Figure 1 (Pearson's correlation, coefficient $r=$ $0.91, p<0.0001)$. The equivalent formula was $\mathrm{X}=\mathrm{Y}^{1.39} \times 1.02 \quad(\mathrm{X}=$ protein concentration, $\mathrm{mg} / \mathrm{dl}$; $\mathrm{Y}=$ laser flare intensity, photon counts $/ \mathrm{ms}$ ). There was no difference in actual protein concentration between non-diabetics and diabetics without retinopathy as shown in Table 3 . However, a significant increase in aqueous protein concentration was confirmed in diabetics with background and proliferative retinopathy, especially in rubeosis iridis (Wilcoxon rank sum test, $\mathrm{p}<0.05$ ).

\section{Discussion}

In this study, a significant increase of the laser flare intensity was found in later decades of normal subjects using the flare cell meter. Increase of the flare intensity with age has been reported previously. ${ }^{1213} 18$ The factor contributing to this increase may be the dysfunction of the 
blood-aqueous barrier shown by histopathological ${ }^{20} 21$ and fluorophotometric studies. ${ }^{22}$ The light reflected from the lenses, anterior chamber volume, and aqueous flow rate does not contribute. ${ }^{1218}$

The increase of laser flare intensity over the sixth decade in diabetics with background retinopathy may reflect the diabetic change in iris vessels ${ }^{1-323}$ (diabetic iridopathy ${ }^{24}$ ) or the ciliary epithelium which is responsible for bloodaqueous barrier. ${ }^{25}$ Iris fluorescein angiography ${ }^{323}$ and fluorophotometric studies ${ }^{4}$ indicated dysfunction of the blood-aqueous barrier in diabetics with retinopathy. Kato et $a l^{26}$ have reported that iridopathy may mainly affect the flare intensity in the background retinopathy group. In older diabetics with background retinopathy, these diabetic changes seem to occur easily in addition to the aging changes previously described. Another possible factor which contributes to the increase in the laser flare intensity in proliferative retinopathy may be the breakdown of the blood-retinal barrier. It has been reported that the laser flare intensity correlated with the extent of the non-perfusion area ${ }^{27}$ or the dilatations and exudative vascular changes in the retina. ${ }^{28} \mathrm{We}$ observed that the flare intensity increased after the onset of vitreous haemorrhage and then decreased gradually. ${ }^{29}$ In eyes with proliferative retinopathy, the breakdown of the blood-retinal barrier was reported to contribute mainly to the increase in flare intensity. ${ }^{26}$ The flare intensity may be affected by proliferative retinopathy directly or indirectly. Large molecules such as proteins or various chemical mediators and growth factors are released from the proliferative retina. These molecules may reach the anterior chamber and result in an increase in the flare intensity. The aqueous flow rate is a further possible factor which affects the laser flare intensity. A significant decrease in the aqueous flow was found in diabetics. ${ }^{30}$ However, this decrease was not correlated with the degree of retinopathy. ${ }^{30}$ Thus, the decrease in aqueous flow rate may not affect the flare intensity. Although pathogenesis of high flare intensity in diabetics remains to be elucidated, a significant increase in the laser flare intensity was observed in the diabetics with retinopathy.

A significant increase in actual protein concentration was found in diabetics with background and proliferative retinopathy, especially in rubeosis cases as observed in the laser flare intensity. However, the equivalent formula obtained from our study was different from reported data using albumin solutions ${ }^{12}$ or aqueous protein in rabbit eyes. ${ }^{31}$ In uveitic eyes the overestimation of aqueous protein concentration using an in vitro calibration curve was reported by Shah et al. ${ }^{32}$ The laser flare intensity depends on the molecular size of proteins in the anterior chamber. The breakdown of the bloodaqueous barrier causes leakage of protein and a change in composition of the aqueous humour. ${ }^{17}$ This change depends on the degree of the breakdown of the blood-aqueous barrier. In diseased eyes, the aqueous flare expressed by the in vitro calibration curve does not give the actual protein concentration. Consequently, it is better to express results in photons/ms rather than to use the in vitro calibration curve in diseased eyes as reported previously. ${ }^{72}$ Nevertheless, the laser flare intensity had a significant correlation with actual aqueous protein concentration in diabetics as shown in Figure 1.

Aqueous flare and cells under slit-lamp examination are clinically important indicators in ocular inflammation and anterior segment surgery. ${ }^{33}$ The laser flare intensity measured with the scattering of a light beam provides precise information not only on inflammation but also on non-inflammatory conditions such as aging or diabetic changes. Our results would suggest that the laser flare intensity (photon counts $/ \mathrm{ms}$ ) reflects actual aqueous protein concentration in diabetics and is a quantitative indicator in the evaluation of the precise diabetic dysfunction of the blood-ocular barrier without tracers.

1 Taniguchi Y, Sameshima M. Fine structure of small blood vessel in the iris of human diabetics. Acta Soc Ophthalmol 1971; 75: 1685-97.

2 Ishibashi $\mathrm{T}$, Tanaka $\mathrm{K}$, Taniguchi $\mathrm{Y}$. Disruption of iridia blood aqueous barrier in experimental diabetic rats. Graefes Arch Clin Exp Ophthalmol 1982; 219: 159-64.

3 Klein S, Marre E, Zenker HJ, Koza KD. Zur Korrelation von diabetischer Irido-und retinopathie. Fortschr Ophthalmol 1983; 79: 428-30

4 Waltman SR, Oestrich C, Krupin T, Hanish S, Ratzan S, Santiago J, et al. Quantitative vitreous fluorophotometry. A sensitive technique for measuring early breakdown of the blood-retinal barrier in young diabetic patients. Diabetes 1978; 27: 85-7.

5 Sawa M, Tsurimaki Y, Tsuru T, Shimizu H. New quantitative method to determine protein concentration and cell number in aqueous in vivo. $\mathcal{F}$ pn $\mathcal{F}$ Ophthalmol 1988; 32: 132-42.

6 Ohara K, Okubo A, Miyazawa A, Miyamoto T, Sasaki H, Oshima $F$. Aqueous flare and cell measurement using lase in endogenous uveitis patients. Fpn F Ophthalmol 1989; 33: 265-70.

7 Sawa M. Clinical application of laser flare-cell meter. $\mathcal{f} p n \mathcal{F}$

8 El-Maghraby A, Marzouki A, Matheen TM, Souchek J, Karr MVD. Reproducibility and validity of laser flare-cell meter measurements as objective method of assessing intraocular inflammation. Arch Ophthalmol 1992; 110: 960-2.

9 Kuchle M, Nguyen NX, Horn F, Naumann GOH. Quantitative assessment of aqueous flare and aqueous cells in pseudoexfoliation syndrome. Acta Ophthalmol 1992; 70: 201-8.

10 Miyake K, Miyake T, Kayazawa F. Blood aqueous barrier in eye with retinal vein occlusion. Ophthalmology 1992; 99 906-10.

11 Nguyen IUX, Kuchle M. Aqueous flare and cells in eyes with retinal vein occlusion-correlation with retinal fluorescein angiographic findings. Brf Ophthalmol 1993; 77: 280-3.

12 Oshika T, Kato S, Sawa M, Masuda K. Aqueous flare intensity and age. Fpn $\mathcal{F}$ Ophthalmol 1989; 33: 237-42.

13 Shirabe $H$, Azumi A, Inoue $M$, Yamamoto $M$. Changes in aqueous flare with age in normal eyes, as measured with lase flare cell meter. Folia Ophthalmol fpn 1989; 40: 1249-52.

14 Azumi A, Shirabe $H$, Tetsumoto $K$, Asai $T$, Inoue $M$, Yamamoto $M$. Application of laser flare-cell meter in diabetes mellitus. Folia Ophthalmol fpn 1989; 40: 2494-9.

15 Azumi A, Shirabe H, Inoue M, Yamamoto $M$. Aqueous flare in diabetes and normal subjects. Invest Ophthalmol Vis $S_{c i}$ 1989; 30 (suppl): 79

16 Oshika T, Kato S, Funatsu H. Quantitative assessment of aqueous flare intensity in diabetes. Graefes Arch Clin Exp Ophthalmol 1989; 227: 518-20.

17 Yoshitomi T, Wong AS, Daher E, Sears M. Aqueous flare measurement with laser flare-cell meter. $7 p n \mathcal{F}$ Ophthalmol 1990; 34: 57-62.

18 Shah SM, Spalton DJ, Smith SE. Measurement of aqueous cells and flare in normal eyes. Br F Ophthalmol 1991; 75: 348-52.

19 Bradford $M$. A rapid and sensitive method for the quantitation of microgram quantities for protein utilizing the principle of protein-dye binding. Anal Biochem 1976; 72: 248-54

20 Okamura R, Lutjen-Drecoll E. Elektronenmikroskopische untersuchungen uber die altersveranderunger der menschlichen iris. Graefes Arch Clin Exp Ophthalmol 1973; 186: 249-69.

21 Shimizu T. Electron microscopic studies of age changes in human iris. Part 1. The anterior border layer of glaucomatous eyes. Acta Soc Ophthalmol fpn 1980; 84: 1352-9.

22 Kayazawa F, Tamura S, Tsuji T, Matsuda T, Kuwayama W, Machida T. The influence of aging on vitreous fluorophotoMachida T. The influence of aging on vitreous flu
metry. Acta Soc Ophthalmol fpn 1983; 87: 380-3.

23 metry. Acta Soc Ophthalmol fpn $1983 ; 87: 380-3$. fpn 7 Clin Ophthalmol 1976; 30: 49-54. 24 Clapp CA. Diabetic iridopathy. Am $\mathcal{F}$ Ophthalmol 1945; 28 : 
25 Ikebe H, Terubayashi H, Akagi Y, Kodor PF, Kinoshita JM. Ciliary body changes associate with aldose reductase in galactosemic rats. Acta Soc Ophthalmol 1989; 93: 758-62.

26 Kato S, Oshika T, Funatsu H, Kokutei K, Yamashita H, Sawa $M$. Aqueous protein concentration in diabetics. Report 5 . Relationship between aqueous protein concentration and pathological findings of iridal vessels. Acta Soc Ophthalmol f pn 1992; 96: 1000-6.

27 Kato S, Oshika T, Funatsu H, Katsuro K, Yamashita H, Sawa $M$. Aqueous protein concentration in diabetics 4 . Implication of retinal 1992; 46: 149-53.

28 Schonherr U, Kuchle M, Nguyen NX, Steinhauser B, Naumann GOH. Capillary exudation in diabetic retinopathy and diabetic iridopathy-correlation between fluorescein angiography and laser flare cell meter. Inves Ophthalmol Vis Sci (Suppl) 1992; 33: 1364
29 Azumi A, Inoue $M$, Yamamoto $M$. Application of laser flarecell meter in patients with diabetes mellitus 2, Factors influencing the flare counts. Folia Ophthalmol fpn 1990; 41: influencing

30 Hayashi M, Yablonski ME, Boxrud C, Fong N, Berger C, Javanovic LJ. Decreased formation of aqueous humor in insulin-dependent diabetic patients. Br F Ophthalmol 1989 73: 621-3.

31 Ogawa T, Ohara K, Shimizu H. Correlation between total aqueous protein concentration and photon counts in rabbits. Acta Soc Ophthalmol.7pn 1990; 94: 1001-6.

32 Shah SM, Spalton DJ, Taylor JC. Correlations between laser flare measurements and anterior chamber protein concentrations. Invest Ophthalmol Vis Sci 1992; 33: 2878-84.

33 Dernouchamps JP. The protein of the aqueous humor. Doc Ophthalmol 1982; 53: 193-248.

\section{History of ophthalmology}

\section{Antisepsis in ophthalmology}

Antisepsis came to surgery, and to ophthalmology, in the $1880 \mathrm{~s}$, and like all innovations it was much debated. Its true origins were probably in Vienna, where the obstetric ward staffed by midwives had a reasonable mortality for the time. However, the adjacent ward staffed by medical students, who came directly from the dissecting room, had such a reputation that women assigned to it literally wept and begged to be allowed to die at home. The midwives probably explained this by blaming the gross incompetence of the medical students, until a certain Dr Semmelweiss began to look further. Eliminating differences in patients' social class, food, window opening, degree of noise from the street, etc between the two wards, he decided that students were bringing in some contagion from their dissections, and by introducing them forcibly to bowls of lime chloride he dramatically reduced the mortality.

It was Joseph Lister who, several years later, closed his books after an extensive study of Semmelweiss and Pasteur and decided that airborne organisms must be eliminated by chemical antisepsis. Having seen carbolic acid used as a sewerage disinfectant in Carlisle, he felt it should be adequate for the task and published his findings extensively throughout the 1870s. As various colleagues replicated his results, they were generally accepted.

Von Graefe suggested that antisepsis be used in cataract extraction, and Simeon Snell, returning from holiday to read his account, decided to give the method a trial. For his next dozen patients, eyes were washed preoperatively in $2 \%$ carbolic acid (presumably borrowed from his housekeeper for the occasion) as were instruments and sponges. Boracic acid was applied to the dressings afterwards. (Charles Darwin, momentarily diverted from evolution, suggested the latter substance to Lister.) Snell reported a satisfying lack of suppuration, yet a distressing amount of patient complaint as the solution was applied. Furthermore, the degree of conjunctival swelling made the elevation of the lid technically difficult. Snell, combining theory with practicality, returned the carbolic acid to his cleaner and vowed to use thymol solution in a future series.
By the end of the 1890s, knowledge had advanced, and the prestigious Bowman lecture on ophthalmology summarised the new developments - namely, that normal tissue possessed its own defences, and thus that extremely strong chemical agents should not be used. Furthermore, from experimental insertion of gold and quicksilver into rabbit eyes, it was seen that inflammation could be caused both by infection and also by some (but not all) foreign bodies.

By 1898 , heat sterilisation had arrived and largely replaced chemical antisepsis in eye operations. McGillivray describes his regimen for aseptic cataract extraction in detail. Firstly, the patient had a bath and change of underclothes (and this in itself could be quite a shock to the poorer subject), then a test dressing was applied overnight which must remain unstained for the operation to proceed. The surgeon washed his hands in water, then weak antiseptic, then sterile saline, and superintended the boiling of his instruments for no more than 2 minutes (any longer blunted the scalpel blades, and the cries from hospital surgeons for more than one set of instruments each were piteous). The eye was then laboriously cleaned with a sterile mop, irrigated with streams of saline at $90^{\circ} \mathrm{F}$, flushed out with further saline poured from a height, and the area beneath the lids was attacked with a saline douche.

McGillivray found that saline had a 'soothing' effect when applied to the eye, and in contrast with the howls accompanying direct application of carbolic acid, this was undoubtedly true.

The subject of hand disinfection was investigated by incubating scrapings from beneath the operator's nails. One surgeon found that his own hands, and the nurses' could be sterilised by a moderate sublimate solution. The finding that the house officer was invariably 'contaminated' would have been no surprise to Semmelweiss, but probably led to the prescription of a much more caustic disinfectant for that unfortunate individual.

F ROMAN

Leber MD. Present position of our knowledge of inflammation. Trans Ophthalmol Soc UK 1892; 13: 1-14.

McGillivray A. The aseptic treatment of wounds in cataract surgery. Trans Ophthalmol Soc UK 1898; 18: 320-42. Snell S. Antisepsis in cataract extraction. Br Med $\mathcal{F} 1880$; i: 241. 